\title{
Tandem Mass Spectrometry of Lithium-Attachment Ions from Polyglycols
}

\author{
Robert P. Lattimer \\ The BFGoodrich Research and Development Center, Brecksville, Ohio, USA
}

\begin{abstract}
A detailed study has been carried out of the fast atom bombardment tandem mass spectrometry (MS/MS) behavior of lithium-attachment ions from three glycol polymers: linear poly(ethylene glycol), linear poly(propylene glycol), and an ethoxylated fatty alcohol. Collisional activation was carried out in the "collision octapole" of a BEoQ hybrid mass spectrometer at a translational energy of $50 \mathrm{eV}$, with collision gas air. It was found that $[\mathrm{M}+\mathrm{Li}]^{+}$ions provide a number of advantages as precursors for practical MS/MS analysis as compared to the use of $[\mathrm{M}+\mathrm{H}]^{+}$or $[\mathrm{M}+\mathrm{Na}]^{+}$ions. First, $[\mathrm{M}+\mathrm{Lij}]^{+}$ions are much more intense than the corresponding $[\mathrm{M}+\mathrm{H}]^{+}$ions. Second, $[\mathrm{M}+\mathrm{Li}]^{+}$ions dissociate to lithiated organic fragments with reasonable efficiency, which is not the case with $[\mathrm{M}+\mathrm{Na}]^{+}$ precursors. Third, product ions are generally formed over the entire mass range for low molecular weight polyglycols. The most intense product ions are lithiated, linear polyglycol oligomers. These ions are formed via internal hydrogen transfer reactions which are facilitated by lithium (charge-induced). Two series of less intense product ions are formed via charge-remote fragmentations involving 1,4-hydrogen elimination. A fourth product ion series consists of lithiated radical cations; these form via homolytic bond cleavages near chain ends. Overall, MS/MS analysis of $[\mathrm{M}+\mathrm{Li}]^{+}$polyglycol ions proved to be quite useful for chemical structure elucidation. (] Am Soc Mass Spectrom 1992, 3, 225-234)
\end{abstract}

$\mathrm{N}$ umerous applications of tandem mass spectrometry (MS/MS) in polymer science have been described in recent years. Three specific areas have been considered: (1) identification of organic additives in compounded polymers, (2) identification of volatile pyrolyzates in polymer pyrolysis studies, and (3) characterization of individual oligomers in low molecular weight polymers. In all of these areas, the principal advantage of using MS/MS is that more information is available from mixtures than can be obtained by direct analysis using conventional (single stage) mass spectral methods.

This report focuses on the MS/MS behavior of a particular class of commercially important low molecular weight polymers, hydroxyl-terminated polyglycols: $\mathrm{HO}\left(\mathrm{CH}_{2}-\mathrm{CHR}-\mathrm{O}\right)_{n} \mathrm{R}^{\prime}$. A large number of polyglycols have been studied by mass spectrometry; in recent years most workers have used various "desorption-ionization" methods to effect volatilization and ion production. Several reports have included some description of polyglycol MS/MS behavior. Collisional dissociation of $[\mathrm{M}-\mathrm{H}]^{-}$ions from an ethylene glycol/propylene glycol copolymer was studied using chemical ionization (CI/MS/MS) [1]. Product

Address reprint requests to Robert P. Lattimer, BFGoodrich Research and Development Center, 9921 Brecksville Road, Brecksville, OH 44141. ions showing consecutive losses of ethylene oxide (EO) or propylene oxide (PO) were described. Sodium-attachment ions from an ethoxylated dodecyl alcohol were studied by field desorption (FD/MS/MS); collisional activation was said to produce a "very unspecific fragmentation" [2]. $[\mathrm{M}+\mathrm{H}]^{+}$ions from an ethoxylated fatty amine and an ethoxylated alkyl phenol were found to yield structurally significant product ions (FD/MS/MS); these included consecutive losses of EO groups [3, 4]. Some product ion scans (electron ionization MS/MS) for an unspecifed "antistatic agent" containing poly(ethylene glycol) were presented with no interpretation [5]. An ethoxylated alkyl sulfate (anionic surfactant) was studied by fast atom bombardment (FAB/MS/MS) [6]. The number of EO groups contained in a specific oligomer could be deduced from the product ion spectrum. An ethoxylated quaternary amine (cationic surfactant) was also studied by using FAB/MS/MS [7]. Sequential losses of $\mathrm{EO}$ units from the amine cation were reported.

Earlier work from our laboratory investigated in some detail the MS/MS behavior of $[\mathrm{M}+\mathrm{H}]^{+}$and $\left[\mathrm{M}+\mathrm{Na}^{+}\right.$ions from linear poly(ethylene glycol), PEG, and poly(propylene glycol), PPG [8]. The [M + $\mathrm{H}]^{+}$ions fragmented readily under low energy collisional activation $(\approx 50 \mathrm{eV})$, but the product ions formed were of relatively low mass; hence these were of limited value for chemical structure elucidation. 
The $[\mathrm{M}+\mathrm{Na}]^{+}$ions, while generally quite intense, were found to be very stable towards cleavage of $\mathrm{C}-\mathrm{O}$ and $\mathrm{C}-\mathrm{C}$ bonds. Only very weak sodiated organic product ions were formed, even at a relatively high translational energy $(3 \mathrm{keV})$, with collision gas air. Thus it was found that neither $[\mathrm{M}+\mathrm{H}]^{+}$nor $[\mathrm{M}+$ $\mathrm{Na}]^{+}$ions were optimal for practical MS/MS analysis of polyglycols [8]. In recent work it was shown that one approach for increasing the collisional dissociation efficiency of $[\mathrm{M}+\mathrm{Na}]^{+} \mathrm{PEG}$ ions is to use a more massive collision gas (xenon) [9].

The principal thrust of the current study was to investigate the analytical utility of collisional dissociation of lithium-attachment polyglycol ions. A search of the literature showed that MS/MS of $[\mathrm{M}+\mathrm{Li}]^{+}$or $\left[\mathrm{M}+\mathrm{Li}_{2}-\mathrm{H}\right]^{+}$ions can give rich product ion spectra that are useful for structure elucidation. Adams, for example, has recently reviewed the class of gas-phase reactions called charge-remote fragmentations [10]. These MS/MS reactions often proceed readily with lithiated precursor ions. Compound classes investigated include fatty alcohols [11], fatty acids [12-14], peptides [15-17], and oligosaccharides [18]. In all of these cases abundant product ions were formed, from lithiated precursors, which proved useful in chemical structure elucidation. It was hoped that similar results could be obtained with polyglycols.

\section{Experimental}

A Finnigan-MAT (Bremen, Germany) $95 \mathrm{Q}$ hybrid mass spectrometer of $\mathrm{BEoQ}$ geometry was used for analysis. Collisional activation was carried out in the "collision octapole" with translational energy $\left(\mathrm{E}_{\text {lab }}\right)$ of $50 \mathrm{eV}$ and collision gas air. The pressure in the collision cell was adjusted to $\approx 0.2 \mathrm{~Pa}$, which corresponds to a pressure in the quadrupole analyzer region of $\approx 8 \times 10^{-4} \mathrm{~Pa}$. For PEG or PPG under these conditions, the most abundant product ions were $\approx 20 \%$ of the $[\mathrm{M}+\mathrm{Li}]^{+}$precursor ion intensity. At higher cell pressures or higher translational energies, more collisional dissociation could be induced, but the product ion scans started to become overly complex owing to the introduction of less specific fragment ions.

The MS/MS experiments were carried out using FAB ionization. The fast atom gun provided xenon atoms at $8 \mathrm{keV}$ energy. The aluminum $\mathrm{FAB}$ target was introduced via the direct probe inlet. Key instrument parameters were as follows: accelerating voltage $5 \mathrm{kV}$, magnetic sector resolution $\approx 800$, and ion source temperature $\approx 30^{\circ} \mathrm{C}$. The mass-separating quadrupole was generally operated at "unit resolution" using the $50 \%$ valley definition. Scans for both the magnetic sector and mass-separating quadrupole were controlled by the data system; data acquisition and output were also under computer control. In typical experiments, profile data were acquired while the quadrupole was scanned at a rate of $100 \mathrm{u} / \mathrm{s}$. About
50-100 product ion scans were accumulated to obtain a composite spectrum, which was then smoothed with a three- or five-point function.

Three low-mass polyglycols were examined: PEG 600 (J. T. Baker Chemical, Phillipsburg, NJ), PPG 750 (Dow Chemical USA, Midland, MI), and Neodol 25-7 (Shell Chemical Co., Houston, TX). PEG 600 and PPG 750 are linear homopolymers that are hydroxylterminated at both ends. The numbers refer to the (number) average molecular weight supplied by the manufacturer. Neodol $25-7$ is an ethoxylated mixed fatty alcohol. The viscous liquid samples were placed directly on the FAB target for analysis. In some cases, $1 \mu \mathrm{L}$ of a saturated solution of $\mathrm{NaI}$ or $\mathrm{LiBr}$ in methanol was added (to effect cation attachment). Deuterated polyglycol samples, $\mathrm{DO}\left(\mathrm{C}_{m} \mathrm{H}_{2 m}-\mathrm{O}\right)_{n} \mathrm{D}$, were prepared by mixing PEG or PPG with a large excess of $\mathrm{D}_{2} \mathrm{O}$ (99.8 atom \% D, Merck, Sharp \& Dohme Isotopes, Dorval, Quebec) in a vial. The water was then evaporated over a stream of dry nitrogen at room temperature. Lithium bromide, when added to the deuterated polyglycols for analysis, was prepared as a solution in $\mathrm{D}_{2} \mathrm{O}$.

\section{Results and Discussion}

\section{Poly(ethylene glycol)}

Figure 1 is the product ion scan of $m / z 465$ from PEG 600 with added $\mathrm{LiBr}$. This is $[\mathrm{M}+\mathrm{Li}]^{+}$for the decamer: ${ }^{7} \mathrm{Li}\left[\mathrm{HO}\left(\mathrm{C}_{2} \mathrm{H}_{4}-\mathrm{O}\right)_{10} \mathrm{H}\right]^{+}$. Figure 2 is the product ion scan for $m / z 467$ from $d_{2}$-PEG with added $\mathrm{LiBr}$. This is $[\mathrm{M}+\mathrm{Li}]^{+}$for the $d_{2}$-decamer: ${ }^{7} \mathrm{Li}\left[\mathrm{DO}\left(\mathrm{C}_{2} \mathrm{H}_{4}\right.\right.$ O) $\left.{ }_{10} \mathrm{D}\right]^{+}$. It is noteworthy that reasonably intense, characteristic fragment ions are observed throughout the entire mass range. This is in contrast to product ion scans acquired under similar conditions for [M + $\mathrm{H}^{+}$(which showed only low mass fragment ions) and $[\mathrm{M}+\mathrm{Na}]^{+}$(which showed only very weak organic-containing fragment ions) [8]. Four ion series (A, B, C, and D) are marked in the two figures. The origins of these series are discussed below.

A series. The A series ions are lithiated, linear oligomers of ethylene glycol:

$$
\mathrm{Li}\left[\mathrm{HO}\left(\mathrm{C}_{2} \mathrm{H}_{4}-\mathrm{O}\right)_{n} \mathrm{H}\right]^{+} m / z 44 n+25
$$

Lithium (Li) is placed outside the bracket, since its site(s) of attachment to the molecule is uncertain. The integer $n$ is the number of $\mathrm{C}_{2} \mathrm{H}_{4} \mathrm{O}$ repeat units. For the deuterated molecule, the product ions up to and including the octamer $(m / z 378)$ are predominately singly deuterated:

$$
\mathrm{Li}\left[\mathrm{DO}\left(\mathrm{C}_{2} \mathrm{H}_{4}-\mathrm{O}\right)_{n} \mathrm{H}\right]^{+} m / z 44 n+26
$$

The fact that abundances of doubly deuterated product ions are very low argues against any mechanism 


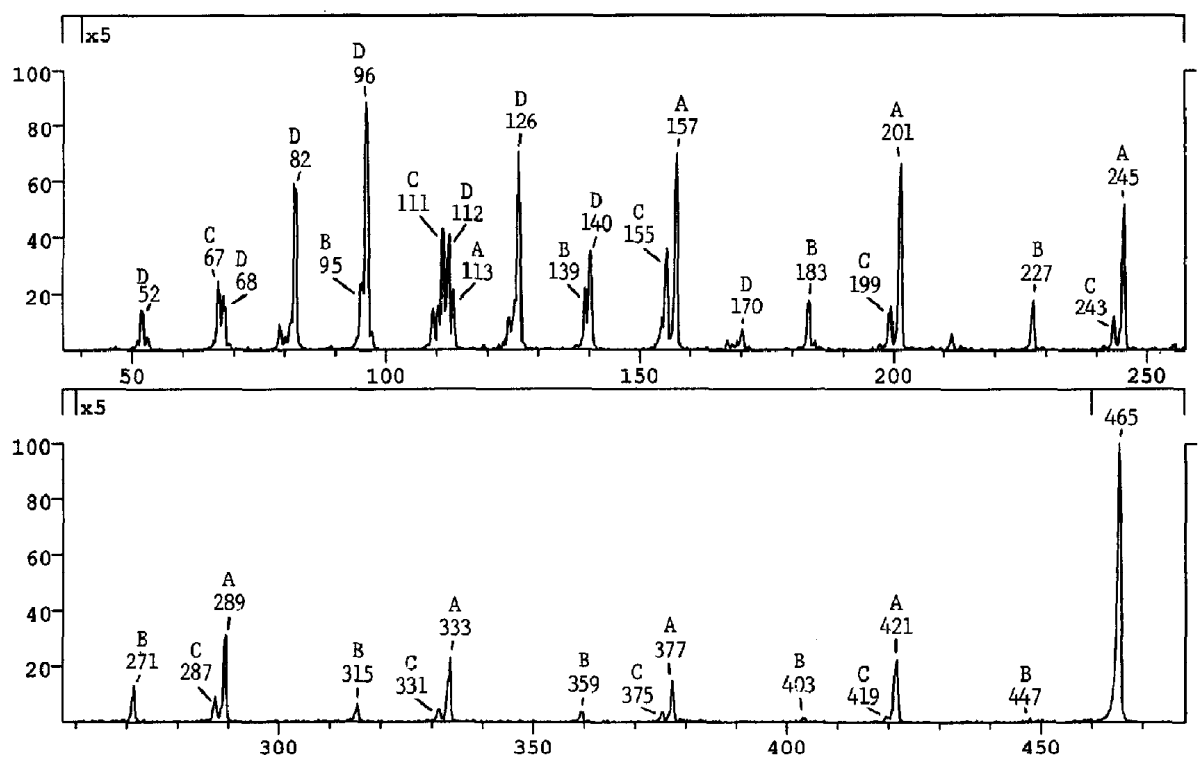

Figure 1. Product ion scan (FAB/MS/MS) of $[\mathrm{M}+\mathrm{Li}]^{+} 465$ (ethylene glycol decamer)
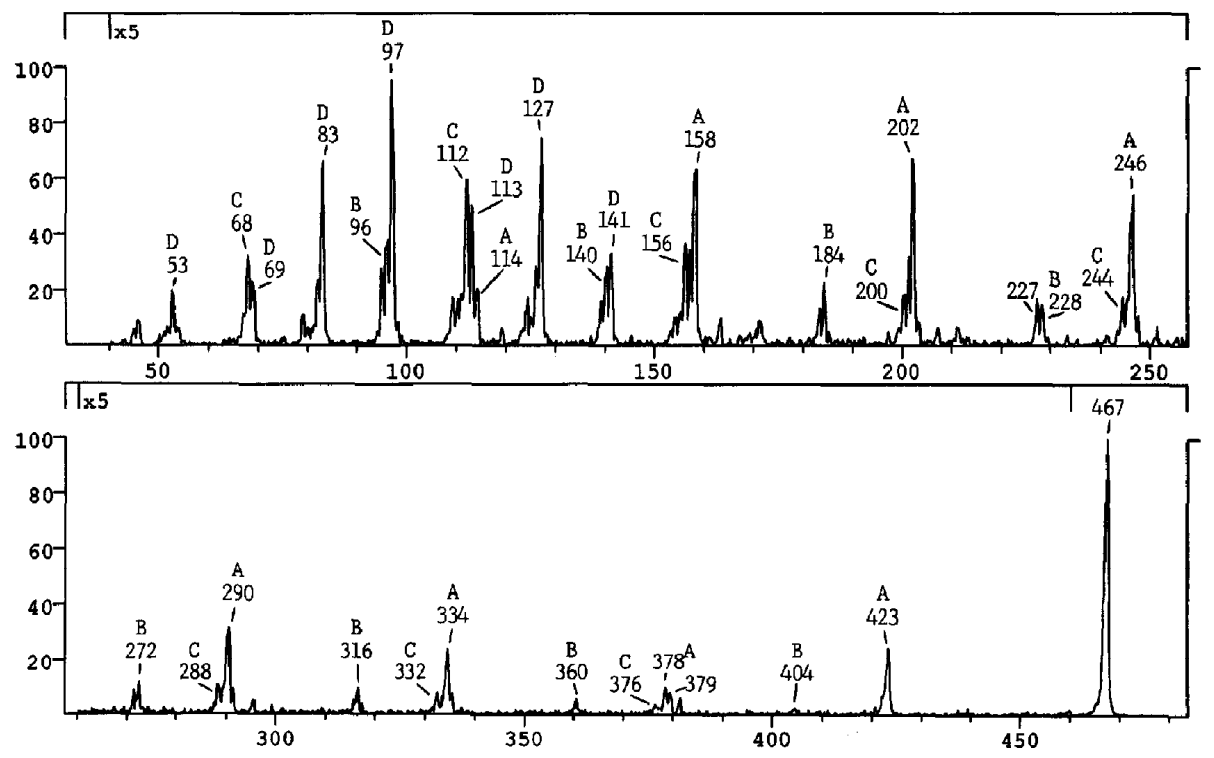

Figure 2. Product ion scan (FAB/MS/MS) of $\left[\mathrm{M}+\mathrm{Li}^{+} 467\right.$ (ethylene glycol decamer- $d_{2}$ ). 
(e.g., intramolecular exchange) involving the elimination of internal ethylene oxide units. Thus the formation of the A series product ions must involve transfer of a hydrogen atom during cleavage of the precursor ion chain. A likely mechanism for this rearrangement is shown in Scheme $I$, in which the $d_{2}$ molecule is used for illustration. A six-membered ring intermediate is envisioned, since this generally provides the lowest energy pathway for internal hydrogen rearrangements. Ethylene and a formyl-terminated ethylene glycol oligomer are the neutral products of the reaction.

It is likely that lithium plays some specific role in facilitating this concerted reaction. This is indicated by a couple of observations. First, one might envisage the same concerted reaction occurring as a charge-remote fragmentation. In this case, referring to Scheme II, two type of oligomers would be produced: (1) a hydroxyl-terminated $\mathbf{A}$ series and (2) a formylterminated $C$ series. Depending upon which side of the precursor ion the lithium happened to reside, one would get either an $\mathbf{A}$ or a $\mathbf{C}$ series ion from this rearrangement. Statistically in this scenario, the $\mathbf{A}$ and $C$ series should be of similar abundance in the product ion spectrum. Since the A series ions are in fact much more abundant than the $\mathbf{C}$ series ions (see Figures 1 and 2), this indicates that lithium plays some specific charge-induced role in promoting the formation of A series ions.

The second observation is that analogous reactions were not reported in earlier studies of PEG $[\mathrm{M}+\mathrm{H}]^{+}$ and $[\mathrm{M}+\mathrm{Na}]^{+}$ions [8]. Collisional dissociation of $[\mathrm{M}+\mathrm{H}]^{+}$was of the classical "charge-site" initiation type (inductive effect), whereas dissociation of $[\mathrm{M}+$ $\mathrm{Na}]^{+}$was of the "charge-remote" fragmentation type (with 1,4-elimination of hydrogen). Because $\mathbf{A}$ and $\mathbf{D}$ series ions were not detected in this earlier study, we decided to reinvestigate the collisional dissociation of $[\mathrm{M}+\mathrm{Na}]^{+}$ions by using the MAT $95 \mathrm{Q}$ mass spectrometer. The experimental conditions were the same as described earlier in the Experimental section. For $[\mathrm{M}+\mathrm{Na}]^{+} 481$ (PEG decamer), the only abundant product ion observed was $m / z 23\left(\mathrm{Na}^{+}\right)$. While very weak sodiated organic product ions corresponding to the A, B, C, and D series could be detected after accumulating several scans, their abundances at most

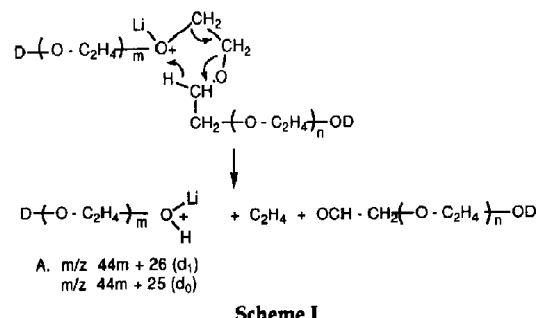

Scheme I

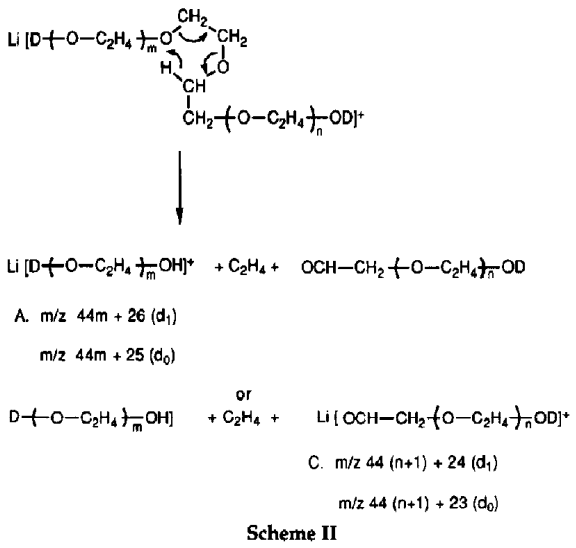

were $\approx 0.5 \%$ of the precursor ion intensity. Also, the A series ions were not at all prominent compared to the other series. It was clear that sodium showed no special tendency to promote the formation of $\mathbf{A}$ series ions.

Note that in the earlier study [8] the formation of $m / z 23$ was not observed because the quadrupole was not scanned below $m / z 50$. Thus, it is now clear that $[\mathrm{M}+\mathrm{Na}]^{+}$is not stable towards collisional dissociation, as previously proposed [8], but instead preferentially loses $\mathrm{Na}^{+}$rather than fragmenting via the alternative, higher energy (charge-remote) routes.

Thus it seems probable that the hydrogen rearrangement leading to A series ions is "charge-induced" by lithium, rather than "charge-remote" in nature. In Scheme I, the lithium atom is shown to be attached to the oxygen that abstracts the hydrogen atom during rearrangement. This type of intermediate seems most consistent with the product ion data. It should be noted that $\mathrm{Li}^{+}$may be coordinated to more than one oxygen atom; one cannot make this distinction from the MS/MS data. The fact that the A series ions are observed throughout the entire mass range indicates that lithium can attach itself to oxygen atoms all along the PEG chain. Because the lower mass oligomers are more intense, however, there may be some preference for attachment of lithium near chain ends.

One further observation is of note. While all of the oligomers up to octamer show minor abundances of the $d_{2}$ species, it is interesting that the nonamer $(\mathrm{m} / \mathrm{z}$ 423 , Figure 2) is almost entirely doubly deuterated. This may be explained by a logical extension of Scheme I to the end ethylene oxide group:

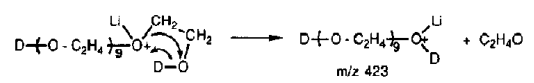

In this case it is clear that only the hydroxyl hydrogen 
(or deuterium) is readily available for transfer in forming the $m / z 423$ product ion.

One final competitive mechanism is deserving of consideration; this is the direct dissociation (disproportionation) of $[\mathrm{M}+\mathrm{Li}]^{+}$. In this case, referring to Scheme III, two types of oligomers would be produced: (1) a hydroxyl-terminated $\mathbf{A}$ series and (2) a vinyl-terminated $B$ series. If this were a charge-remote fragmentation, one would get either an A or a B series ion from this rearrangement, depending upon which side of the precursor ion the lithium happened to reside. Statistically then, one would expect the $\mathbf{A}$ and B series to be of similar abundance. The fact that the A series ions are much more abundant argues against Scheme III as a charge-remote reaction. One might also consider Scheme III as a charge-induced reaction. However (as noted in the preceding paragraph), the elimination of $\mathrm{C}_{2} \mathrm{H}_{4} \mathrm{O}$, rather than $\mathrm{C}_{2} \mathrm{H}_{3} \mathrm{OD}$, from the $d_{2}-[\mathrm{M}+\mathrm{Li}]^{+}$precursor seems to argue against this type of mechanism as either a charge-remote or a charge-induced reaction.

$B$ and $C$ series. The $B$ and $C$ series ions are most likely formed via charge-remote fragmentations, as shown in Scheme IV (the $d_{2}$ molecule is used for illustration). These reactions are analogous to the charge-remote decompositions described earlier for PEG $[\mathrm{M}+\mathrm{Na}]^{+}$ions [8]. The ions from the dideutero precursor (Figure 2) are shifted as expected to massto-charge ratio values $1 \mathrm{u}$ higher than for the $d_{0}$ precursor (Figure 1). The mechanism shown in Scheme IV involves a 1,4-hydrogen elimination with the formation of two terminally unsaturated chains. For PEG, lithium-attachment ions can be formed with either a vinyl (B series) or formyl (C series) end group. Note that the $B$ and $C$ series ions are of similar intensities, which would be expected from the reaction described in Scheme IV. Note also that the $B$ and C series ions in Figures 1 and 2 are considerably weaker than the A series fragments. This is logical
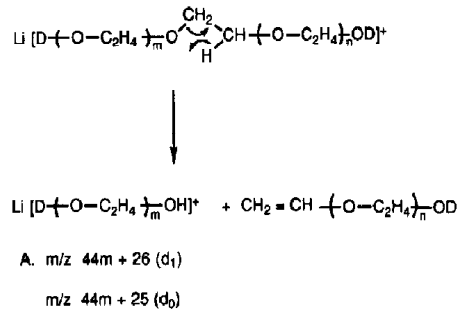

Scheme III

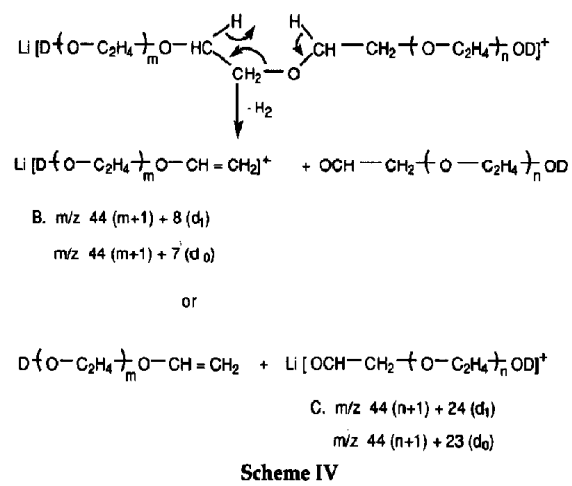

since charge-induced reactions (which form the A series ions) are generally energetically favored over charge-remote pathways.

$D$ series. From the pattern of the $\mathbf{D}$ series ions, it is evident that these are radical cations containing lithium:

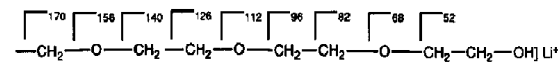

This scheme suggests that these ions form via homolytic bond cleavages near chain ends containing lithium. The product ions formed from the dideutero precursor (Figure 2) are shifted as expected $1 \mathrm{u}$ higher as compared to the $d_{0}$ precursor (Figure 1). The product ions are at least formally distonic (i.e., having the charge separated from the radical site). Of course rearrangement may occur to form other structures. The formation of $\mathrm{D}$ series ions is apparently specific for $[\mathrm{M}+\mathrm{Li}]^{+}$precursors; analogous product ions were found to be extremely weak for PEG $[\mathrm{M}+\mathrm{Na}]^{+}$ ions.

There is some precedence in the literature for this type of fragmentation. $[\mathrm{M}+\mathrm{Li}]^{+}$ions for fatty alcohols, for example, were found to give product ions of the type $\left[\cdot \mathrm{C}_{n} \mathrm{H}_{2 n}{ }^{-} \mathrm{OHLi}\right]^{+}$[11]. Low mass radical cations have also been described as product ions from lithiated fatty acid precursors [12-14].

\section{Poly(propylene glycol)}

Figure 3 is the product ion scan of $m / z 489$ from PPG 750 with added $\mathrm{LiBr}$; this is $[\mathrm{M}+\mathrm{Li}]^{+}$for the octamer: $\mathrm{Li}\left[\mathrm{HO}\left(\mathrm{CH}_{2}-\mathrm{CHCH}_{3}-\mathrm{O}\right)_{8} \mathrm{H}\right]^{+}$. Figure 4 is the product ion scan for $m / z 491$ from $d_{2}$-PPG with added $\mathrm{LiBr}$; this is $[\mathrm{M}+\mathrm{Li}]^{+}$for the $d_{2}$-octamer. Four ion series (A, B, C, and D) are marked in the two figures. These series are analogous to those observed for PEG (Figures 1 and 2). Overall it is clear that the product ions formed via collisional dissociation of 

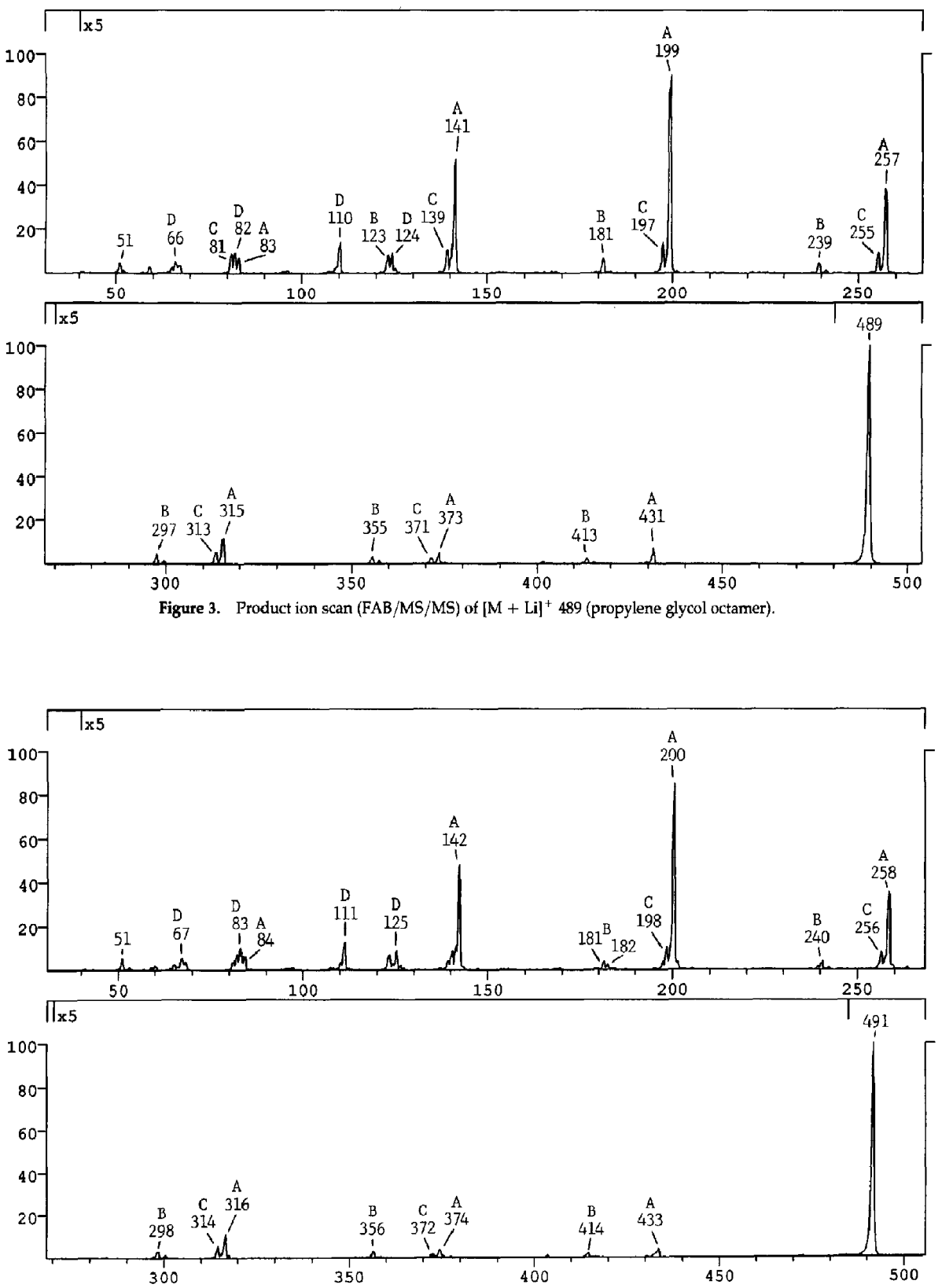

Figure 4. Product ion scan (FAB/MS/MS) of $[M+L i]^{+} 491$ (propylene glycol actamer- $d_{2}$ ). 
PPG $\left[\mathrm{M}+\mathrm{Li}^{+}\right.$ions are very similar to those observed for PEG $[\mathrm{M}+\mathrm{Li}]^{+}$.

A series. The $\mathbf{A}$ series ions are lithiated, linear oligomers of PPG:

$$
\mathrm{Li}\left[\mathrm{HO}\left(\mathrm{CH}_{2}-\mathrm{CHCH}_{3}-\mathrm{O}\right)_{n} \mathrm{H}\right]^{+} m / z 58 n+25
$$

For the deuterated molecule, the product ions up to and including the hexamer $(m / z$ 374) are all singly deuterated:

$$
\mathrm{Li}\left[\mathrm{DO}\left(\mathrm{CH}_{2}-\mathrm{CHCH}_{3}-\mathrm{O}\right)_{n} \mathrm{H}\right]^{+} m / z 58 n+26
$$

The formation of these product ions may be explained by charged-induced hydrogen transfer reactions proceeding through a six-membered ring intermediate. These reactions are analogous to those for the A series in PEG (Scheme I). Propylene and a formyl- (or it could be acetyl-) terminated propylene glycol oligomer are the neutral products of the concerted reaction. While all of the $d_{2}$-PPG oligomers up to hexamer show minor abundances of the $d_{2}$ species, the heptamer ( $m / z$ 433, Figure 4 ) is almost entirely doubly deuterated. This is logical because only the hydroxyl hydrogen (or deuterium) is readily available for transfer in forming this product ion:

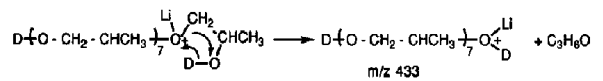

$B$ and $C$ series. The $B$ and $C$ series ions are most likely formed via charge-remote fragmentations. These reactions are analogous to the charge-remote decompositions described earlier for the $\mathbf{B}$ and $\mathbf{C}$ series in PEG (Scheme IV). The product ions from the dideutero precursor (Figure 4) are shifted as expected to mass-to-charge ratio values $1 \mathrm{u}$ higher than for the $d_{0}$ precursor (Figure 3 ). The fragment ions from methine $\mathrm{C}-\mathrm{O}$ cleavage contain either a propenyl (B series) or a formyl (C series) end group:

$$
\begin{aligned}
& \text { B series: } \mathrm{LI}\left[\mathrm{HO}\left(\mathrm{CH}_{2}-\mathrm{CHCH}_{3}-\mathrm{O}\right)_{n} \mathrm{CH}=\mathrm{CHCH}_{3}\right]^{+} \\
& \quad m / z 58(n+1)+7 \\
& \text { C series: } \mathrm{Li}\left[\mathrm{HO}\left(\mathrm{CHCH}_{3}-\mathrm{CH}_{2}-\mathrm{O}\right)_{n} \mathrm{CHCH}_{3}-\mathrm{CHO}\right]^{+} \\
& \quad m / z 58(n+1)+23
\end{aligned}
$$

It may be noted that the end groups would be isopropenyl and acetyl in the case of a methylene C-O cleavage. These experiments do not provide a means to distinguish between these two cases.

$D$ series. The $\mathbf{D}$ series ions are radical cations con- taining lithium:

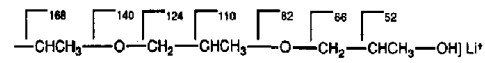

This series is analogous to the D series observed for PEG. One might also expect to observe $D$ series ions from methylol-terminated oligomers: $\mathrm{Li}\left[\mathrm{HO}\left(\mathrm{CH}_{2}\right.\right.$ $\left.\mathrm{CHCH}_{3}-\mathrm{O}\right)_{n} \mathrm{CH}_{2} \cdot \mathrm{J}^{+}$. The fact that these product ions $(m / z 38,96,154)$ are very weak indicates that the majority of chains are terminated by the $\mathrm{HO}$ $\mathrm{CHCH}_{3}$-group.

\section{Ethoxylated Fatty Alcohol}

In an effort to extend the PEG and PPG results to a more complex aliphatic polyglycol, product ion spectra of $[\mathrm{M}+\mathrm{Li}]^{+}$ions from an ethoxylated fatty alcohol (Neodol 25-7) were obtained. An FD mass spectrum of Neodol 25-7, obtained with added NaI, is included as Figure 5. FD/MS is very useful for obtaining a profile of the various oligomers because essentially all ions observed are due to molecular species, in this case $[\mathrm{M}+\mathrm{Na}]^{+}$. The cation selected for $\mathrm{FD} / \mathrm{MS}$ was $\mathrm{Na}^{+}$, rather than $\mathrm{Li}^{+}$, since the $[\mathrm{M}+\mathrm{Na}]^{+}$ions. give a "cleaner" FD mass spectrum. That is, $[M+$ $\mathrm{Li}]^{+}$ions show some tendency to give lithiated organic fragments, which add extra ions to the spectrum. $[\mathrm{M}+\mathrm{Na}]^{+}$ions, on the other hand, fragment almost exclusively by release of $\mathrm{Na}^{+}$. The $\mathrm{FD} / \mathrm{MS}$ data show this material to be a very complex mixture of ethoxylated fatty alcohols:

$$
\mathrm{C}_{m} \mathrm{H}_{2 m+1}-\mathrm{O}\left(\mathrm{C}_{2} \mathrm{H}_{4}-\mathrm{O}\right)_{n} \mathrm{HMW} 14 m+44 n+18
$$

Most of the oligomers are in the range $m=12-16$ and $n=5-8$. The $m$ and $n$ values for some of the $[\mathrm{M}+$ $\mathrm{Na}^{+}$oligomers are marked in Figure 5.

FAB/MS was used to obtain $\left[\mathrm{M}+\mathrm{Li}^{+}\right.$ions for MS/MS. Product ion scans for the $[\mathrm{M}+\mathrm{Li}]^{+} 457$ $(m=12, n=6)$ and $471(m=13, n=6)$ ions are given in Figures 6 and 7 , respectively. The product ions are clearly useful for chemical structure elucidation. Six ion series $\left(\mathbf{A}, \mathbf{A}^{\prime}, \mathbf{B}, \mathbf{B}^{\prime}, \mathbf{C}\right.$, and $\left.\mathbf{D}\right)$ are marked in Figures 6 and 7; these are analogous to the corresponding series for PEG 600 (cf. Figure 1). Four of the ion series (A, B, C, D) are the same for both oligomers, $[\mathrm{M}+\mathrm{Li}]^{+} 457$ and 471 . These series are derived from the PEG end of the molecule, and the masses are the same as those observed for the PEG $[\mathrm{M}+\mathrm{Li}]^{+}$decamer (cf. Figure 1). Note, however, in Figures 6 and 7 that the A, B and C series end with the oligomers containing six ethylene oxide units, since $n=6$ for both $[\mathrm{M}+\mathrm{Li}]^{+} 457$ and 471 .

$A^{\prime}$ series. The $\mathbf{A}^{\prime}$ series contains the intact alkyl group. The mechanism for the formation of these product ions is a rearrangement analogous to that depicted in 

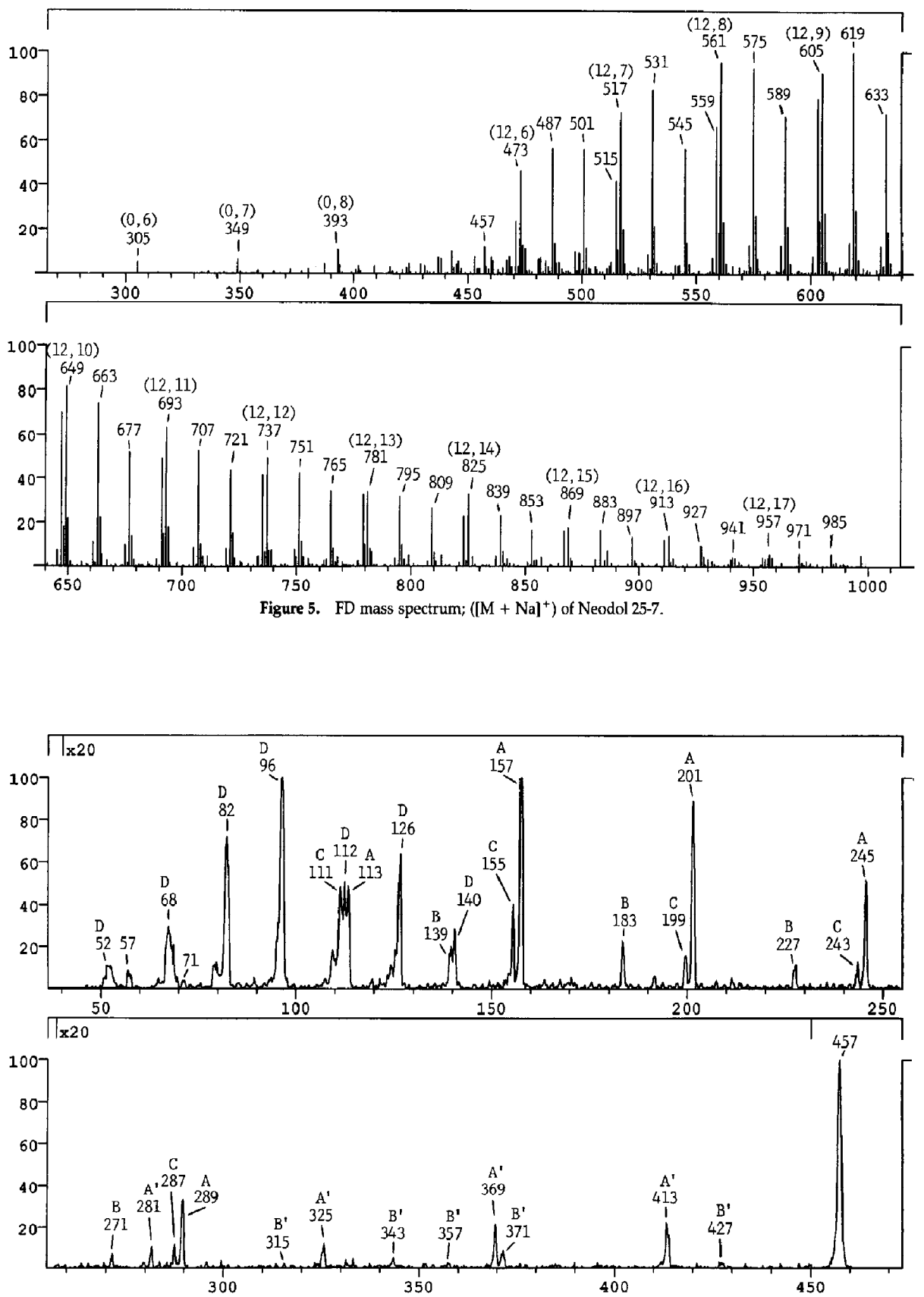

Figure 6. Product ion scan (FAB/MS/MS) of $[\mathrm{M}+\mathrm{Li}]^{+} 457$ (Neodol 25-7; $m=12, n=6$ ). 


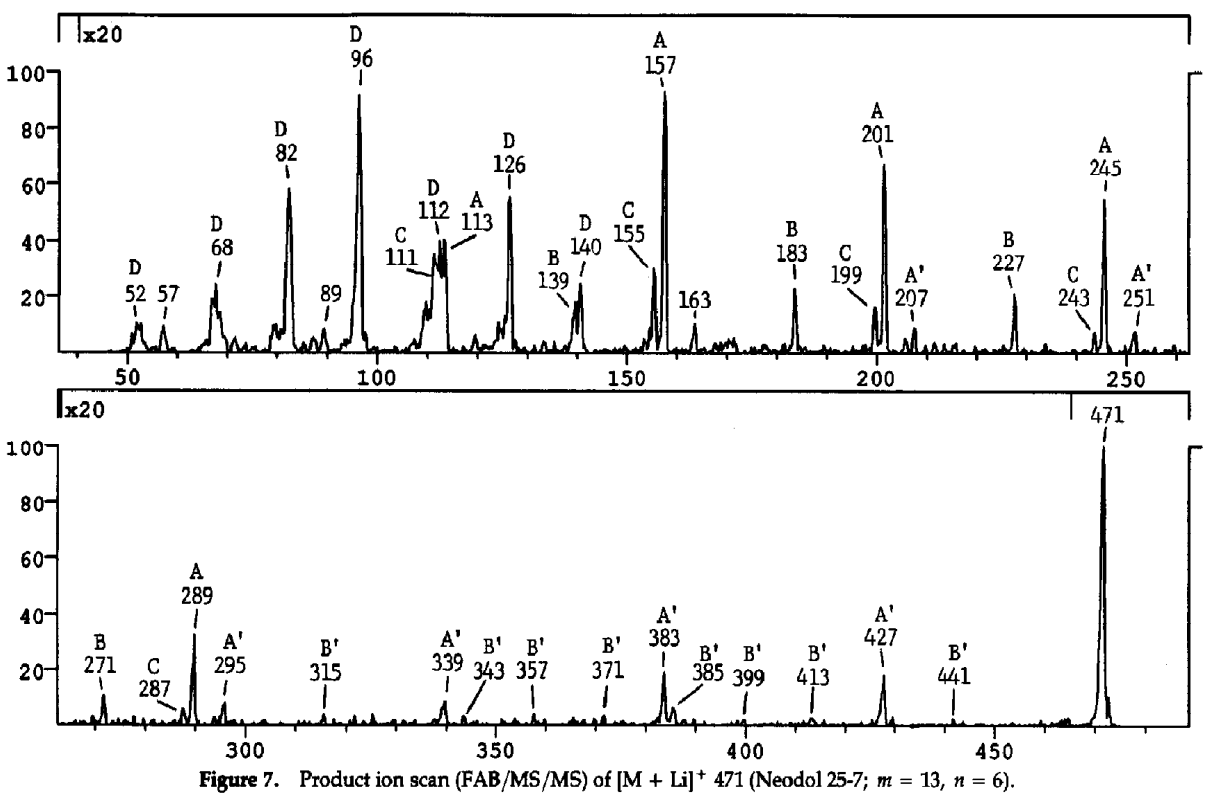

Scheme I for the A series in PEG. Because the alkyl group is $\mathrm{C}_{12} \mathrm{H}_{25}$ for $[\mathrm{M}+\mathrm{Li}]^{+} 457$ (Figure 6) and $\mathrm{C}_{13} \mathrm{H}_{27}$ for $[\mathrm{M}+\mathrm{Li}]^{+} 471$ (Figure 7 ), the $\mathrm{A}^{\prime}$ series is shifted $14 \mathbf{u}$ higher for the latter component:

$$
\begin{aligned}
& \mathrm{Li}\left[\mathrm{C}_{12} \mathrm{H}_{25}-\mathrm{O}\left(\mathrm{C}_{2} \mathrm{H}_{4}-\mathrm{O}\right)_{n} \mathrm{H}\right]^{+} m / z 44 n+193 \\
& \mathrm{Li}\left[\mathrm{C}_{13} \mathrm{H}_{27}-\mathrm{O}\left(\mathrm{C}_{2} \mathrm{H}_{4}-\mathrm{O}\right)_{n} \mathrm{H}\right]^{+} m / z 44 n+207
\end{aligned}
$$

$B^{\prime}$ series. The B' series is relatively weak, and in fact only some of the members are distinct in Figures 6 and 7 . These ions are formed via charge-remote fragmentation in the alkyl portion of the molecule, as depicted in Scheme V. This involves a 1,4-hydrogen elimination via a six-membered ring intermediate. Since the $\mathbf{B}^{\prime}$ series is considerably less intense than the $B$ and $C$ series, it is clear that the 1,4-hydrogen elimination proceeds more facilely in the PEG portion of the molecule (Scheme IV) as compared to the alkyl portion (Scheme V). This is logical considering the

$$
\begin{aligned}
& \text { Li }|\mathrm{H}+\mathrm{O}-\mathrm{C}_{2} \mathrm{H}_{4}+{ }_{\mathrm{H}} \mathrm{O}+\mathrm{CH}_{2} \frac{\mathrm{m}}{\mathrm{m}}_{\mathrm{HC}} \overbrace{\mathrm{CH}_{2}}^{\mathrm{H}}-\mathrm{CH}_{2} \mathrm{CH}_{2}+\mathrm{CH}_{2}+\mathrm{CH}_{3}|^{+} \\
& \text {- } \mathrm{H}_{2} \\
& \left.\mathrm{Li}\left|\mathrm{H}+\mathrm{O} \cdot \mathrm{C}_{2} \mathrm{H}_{4}+\mathrm{k}-\mathrm{O}+\mathrm{CH}_{2} t_{\pi} \mathrm{CH}=\mathrm{CH}_{2}\right|^{+}+\mathrm{CH}_{2}=\mathrm{CH}+\mathrm{CH}_{2}\right)_{\pi} \mathrm{CH}_{3} \\
& \text { g. } m / 244 k+14 m+51
\end{aligned}
$$

relative bond strengths. The $\mathbf{B}^{\prime}$ series ions are analogous to the charge-remote fragmentations in fatty alcohols [11] and fatty acids [12-14], which also involve cleavage of $\mathrm{C}-\mathrm{C}$ bonds.

\section{Summary}

The results of this study show that $[\mathrm{M}+\mathrm{Li}]^{+}$ions provide a number of important advantages as precursors for practical MS/MS analysis of polyglycols as compared to the use of $[\mathrm{M}+\mathrm{H}]^{+}$or $[\mathrm{M}+\mathrm{Na}]^{+}$ions. First, FAB-generated $[\mathrm{M}+\mathrm{Li}]^{+}$ions for polyglycols are generally much more intense than the corresponding $[\mathrm{M}+\mathrm{H}]^{+}$ions. Second, $[\mathrm{M}+\mathrm{Li}]^{+}$ions dissociate to lithiated organic fragments with reasonable efficiency at low collision energy ( $\approx 50 \mathrm{eV}$ ), which is not the case for $[\mathrm{M}+\mathrm{Na}]^{+}$ions. Third, product ions are generally formed over the entire mass range for low molecular weight polyglycols. This feature is especially useful for the chemical structure elucidation of unknown polyglycols.

The reason why $[\mathrm{M}+\mathrm{Li}]^{+}$ions yield superior MS/MS data for polyglycols lies mostly with the energetics. Adams and Gross [13] studied the entire series of alkali cations in an MS/MS study of fatty acids, and for this class of compounds they also concluded that lithium is the superior cation for MS/MS. In studying the energetics, Adams and Gross [13] reasoned that bond energies are an important factor in this phenomenon. That is, the lithium cation is more tightly bound to oxygen in organic molecules than are 
the other alkali metals. Thus, alkali-attachment ions with sodium and the more massive members of the series tend to release the alkali cation preferentially upon collisional activation, leaving the organic molecule as a neutral fragment. Lithium, on the other hand, has a greater tendency to stay attached to the organic molecule. This allows cleavages of the organic portion of the molecule to proceed more readily, leading to lithiated organic product ions $[10,13]$.

These tendencies were apparent in our study of polyglycols. Under the conditions described in the Experimental section, $\mathrm{Li}^{+}$as a product ion was typically $<0.5 \%$ the abundance of the $[\mathrm{M}+\mathrm{Li}]^{+}$precursor. Lithiated organic product ions, on the other hand, had intensities up to $10 \%$ to $20 \%$ of the $[\mathrm{M}+\mathrm{Li}]^{+}$ precursor. Just the opposite was observed with $[\mathbf{M}+$ $\mathrm{Na}]^{+}$precursors. That is, while the $\mathrm{Na}^{+}$intensity was typically $\approx 30 \%$ of the precursor, the sodiated organic product ions were all much less than $1 \%$ the abundance of the $[\mathrm{M}+\mathrm{Na}]^{+}$precursor.

The specific role of lithium in promoting the charge-induced rearrangements that were observed in this study (A series product ions) is at this point unclear. As noted earlier, these rearrangements can occur with $[\mathrm{M}+\mathrm{Na}]^{+}$precursors, but the relative abundances of the $\mathrm{A}$ series ions from $[\mathrm{M}+\mathrm{Li}]^{+}$precursors is much greater than for sodium. These results suggest that loss of $\mathrm{Na}^{+}$from $[\mathrm{M}+\mathrm{Na}]^{+}$is the lowest energy path; the charge-induced reactions of $\left[\mathrm{M}+\mathrm{Li}^{+}\right.$are the next lowest; charge-remote reactions from either $[\mathrm{M}+\mathrm{Na}]^{+}$or $[\mathrm{M}+\mathrm{Li}]^{+}$are next; and loss of $\mathrm{Li}^{+}$is the highest. More work is required to more fully understand this phenomenon.

Overall, it was found that MS/MS analysis of [M $+\mathrm{Li}^{+}$ions from the linear polyglycols (PEG, PPG, Neodol) proved to be quite useful for chemical structure elucidation. It appears that the lithiation MS/MS combination will be a very helpful tool in analyses of selected polar, low molecular weight polymeric materials.

\section{Acknowledgments}

Appreciation is expressed to The BFGoodrich Company for support of this work. Helpful discussions with Professor J. Adams (Emory University) are also acknowledged.

\section{References}

1. Tou, J. C.; Zakett, D.; Caldecourt, V. J. In Tandem Mass Spectrometry; McLafferty, F. W. Ed; John Wiley \& Sons: New York, 1983; p 435.

2. Schneider, E.; Levsen, $K_{1}$; Boerboom, A. J. H.; Kistemaker, P.; McLuckey, S. A.; Przybylski, M. Anal. Chem. 1984, 56, 1987-1988.

3. Weber, R.; Levsen, K.; Louter, G. J.; Boerboom, A. J. H.; Haverkamp, J. Anal. Chem. 1982, 54, 1458-1466.

4. Weber, R.; Levsen, K.; Boerboom, A. J. H.; Haverkamp, J. Int. J. Mass Spectrom. Ion Phys. 1983, 46, 305-308.

5. Catlow, D. A.; Johnson, M.; Monaghan, J. J.; Porter, C.; Scrivens, J. H. J. Chromatogr. 1985, 328, 167-177.

6. Lyon, P. A.; Stebbings, W. L.; Crow, F. W.; Tomer, K. B.; Lippstreu, D. L.; Gross, M. L. Anal. Chem. 1984, 56, 8-13.

7. Lyon, P. A.; Crow, F. W.; Tomer, K. B.; Gross, M. L. Anal. Chem. 1984, 56, 2278-2284.

8. Lattimer, R. P.; Muenster, $H_{\text {; }}$ Budzikiewicz, $H$. Int. J Mass Spectrom. Ion Processes 1989, 90, 119-129.

9. Ross, M. M.; King, F. L.; Wysocki, V. H.; Callahan, J. H. In Proceedings of the 38th ASMS Conference 1990, 1128-1129.

10. Adams, J. Mass Spectrom. Rev. 1990, 9, 141-186.

11. Adams, J.; Gross, M. L. I. Am. Chem. Soc. 1986, 108 6915-6921.

12. Adams, J.; Gross, M. L. Anal. Chem. 1987, 59, 1576-1582.

13. Adams, J.; Gross, M. L. Org. Mass Spectrom. 1988, 23, 307-316

14. Adams, J.; Deterding, L. J.; Gross, M. L. Spectrosc. Int. J. 1987, 5, 199-228.

15. Leary, J. A.; Williams, T. D.; Bott, G. Rapid Commun. Mass Spectrom. 1989, 3, 192-196.

16. Leary, J. A.; Zhou, Z.; Ogden, S. A.; Williams, T. D. I. Am. Soc. Mass Spectrom. 1990, 1, 473-480.

17. Teesch, L. M.; Adams, J. J. Am. Chem. Soc. 1991, 113, 812-820.

18. Zhou, Z.; Ogden, S.; Leary, J. A. J. Org. Chem. 1990, 55, 5444-5446 